\title{
Dampak Lingkungan Terhadap Kejadian Infeksi Parasit
}

\author{
Reqgi First Trasia ${ }^{1^{*}}$ \\ ${ }^{1}$ Bagian Parasitologi, Fakultas Kedokteran, Universitas Sultan Ageng Tirtayasa \\ *Correspondence author: reqgifirsttrasia@gmail.com; Tel: 081514442279 \\ Received: 20 Januari 2021; Accepted: 16 Februari 2021; Published: 10 Maret 2021
}

\begin{abstract}
Abstrak
Penyakit infeksi parasit masih menjadi masalah kesehatan di Indonesia dan di dunia. Pada tahun 2017, World Health Organization (WHO) memasukkan beberapa penyakit parasit ke dalam Neglected Tropical Disease (NTD). Penyakit parasit tidak dapat lepas dari kondisi lingkungan, suhu, kelembaban, iklim, dan lain sebagainya. Di Indonesia, masih sedikit artikel yang meninjau dampak lingkungan terhadap insiden infeksi parasit. Tujuan dari penulisan artikel ini adalah untuk membahas bagaimana suhu, kelembaban dan cuaca dapat memengaruhi angka prevalensi penyakit akibat parasit.
\end{abstract}

Kata kunci: Infeksi parasit, kecacingan, parasitologi, kesehatan lingkungan

\section{Pendahuluan}

Di Indonesia, prevalensi askariasis (penyakit infeksi kecacingan) cukup tinggi, terutama pada anak. Frekuensinya 60-90\%. Kurangnya pemakaian jambab keluarga menimbulkan pencemaran tanah dengan tinja di sekitar halaman rumah, di bawah pohon, di tempat mencuci dan di tempat pembuangan sampah. Di negara-negara tertentu, terdapat kebiasaan memakai tinja sebagai pupuk. Tanah liat, kelembaban tinggi dan suhu 25-30 C merupakan kondisi yang sangat baik untuk berkembangnya telur cacing Ascaris lumbricoides, Trichuris trichiura, Necator americanus, Ancylostoma duodenale, dll menjadi bentuk infektif. Di Indonesia, masih sedikit artikel yang meninjau dampak lingkungan terhadap insiden infeksi parasit. Tujuan dari penulisan artikel ini adalah untuk membahas bagaimana suhu, kelembaban dan cuaca dapat memengaruhi angka prevalensi penyakit akibat parasit, seperti kecacingan, infeksi protozoa, infestasi tungau, dan invasi jamur ke dalam tubuh manusia. [1] 


\section{Soil-Transmitted Helminth}

Insiden tinggi ditemukan pada penduduk di Indonesia, terutama di daerah pedesaan, khususnya di perkebunan. Seringkali pekerja perkebunan yang langsung berhubungan dengan tanah mendapat infeksi lebih dari $70 \%$. Kebiasaan defekasi di tanah dan pemakaian tinja sebagai pupuk kebun (di beberapa daerah tertentu) penting dalam penyebaran infeksi. Tanah yang baik untuk pertumbuhan larva ialah tanah gembur (pasir dan humus) dengan suhu optimum untuk Necator americanus 28-32 C, sedangkan untuk Ancylostoma duodenale lebih rendah (23-25 C). Pada umumnya A.duodenale lebih kuat. Untuk menghindari infeksi, antara lain dengan memakai sandal atau sepatu. [2]

Faktor penting untuk penyebaran penyakit adalah kontaminasi tanah dengan tinja. Telur tumbuh di tanah liat, lembab, dan teduh dengan suhu optimum 30 C. Pemakaian tinja sebagai pupuk kebun merupakan sumber infeksi. Frekuensi di Indonesia cukup tinggi. Di beberapa daerah pedesaan di Indonesia frekuensinya berkisar 30-90 \%. Di daerah yang sangat endemik, infeksi dapat dicegah dengan pengobatan penderita trikuriasis, pembuatan jamban yang baik, pendidikan tentang sanitasi dan kebersihan perorangan, terutama anak-anak. Mencuci tangan sebelum makan dan mencuci sayuran yang dimakan mentah adalah penting, apalagi di negeri yang memakai tinja sebagai pupuk. [3]

Daerah yang panas, kelembaban tinggi dan sanitasi yang kurang, sangat menguntungkan cacing Strongyloides sehingga terjadi daur hidup yang tidak langsung. Tanah yang baik untuk pertumbuhan larva ialah tanah gembur, berpasir dan humus. Frekuensi di Jakarta pada tahun 1996 sekitar 10-15\%, sekarang jarang ditemukan. Pencegahan strongiloidiasis terutama tergantung pada sanitasi pembuangan tinja dan melindungi kulit dari tanah yang terkontaminasi misalnya dengan memakai alas kaki. Penerangan kepada masyarakat mengenai cara penularan dan cara pembuatan serta pemakaian jamban juga penting untuk pencegahan infeksi. [4]

Dampak infeksi cacing yang ditularkan melalui tanah pada masyarakat perlu dipelajari untuk dapat menentukan cara pencegahan. Penyebaran infeksi Ascaris dan Trichuris mempunyai pola yang hampir sama. Demikian juga epidemiologi cacing tambang dan Strongyloides. Beberapa survei di Indonesia menunjukkan bahwa seringkali prevalensi Ascaris yang tinggi disertai prevalensi Trichuris yang tinggi pula. Prevalensi Ascaris yang lebih tinggi dari $70 \%$ ditemukan antara lain di beberapa desa di Sumatra (78\%), Kalimantan (79\%), Sulawesi (88\%), Nusa 

yaitu untuk masing-masing daerah sebesar 83\%. [5]

Table 1. Dampak Lingkungan Terhadap Bentuk Infektif Cacing

\begin{tabular}{llll}
\hline Spesies cacing & Perkembangan di tanah & $\begin{array}{l}\text { Suhu } \\
\text { Optimum }\end{array}$ & $\begin{array}{l}\text { Ketahanan } \\
\text { bentuk infektif }\end{array}$ \\
\hline A.lumbricoides & $\begin{array}{l}\text { Telur matang dalam 3 minggu di } \\
\text { tanah liat. }\end{array}$ & 25-30 C & Sangat tahan \\
\hline T.trichiura & Telur matang dalam 3-6 minggu & 30 C & 1 minggu \\
\hline Cacing tambang & $\begin{array}{l}\text { Telur menetas, dalam 24-36 jam 23-30 C } \\
\text { keluar larva rhabditiform yang pada } \\
\text { hari ke 5-8 menjadi larva filariform di } \\
\text { pasir }\end{array}$ & $\begin{array}{l}7-8 \text { minggu dalam } \\
\text { keadaan baik }\end{array}$ \\
\hline S.stercoralis & $\begin{array}{l}\text { Dalam 36-48 jam terbentuk larva } \\
\text { filariform di tanah pasir. Ada siklus } \\
\text { bentuk bebas di tanah. }\end{array}$ & & \\
& & & $1-2$ minggu \\
& & &
\end{tabular}

Di daerah kumuh di Jakarta, infeksi Ascaris dan Trichuris sudah ditemukan pada bayi berumur kurang dari 1 tahun. Pada usia di atas 1 tahun, A.lumbricoides dapat ditemukan 80-100\% di antara kelompok anak ini. Untuk T.trichiura angkanya lebih rendah sedikit, yaitu $70 \%$. Usia anak yang termuda mendapatkan infeksi Ascaris adalah 16 minggu, sedangkan untuk Trichuris adalah 41 minggu. Ini terjadi di lingkungan anak yang berdefekasi di saluran air terbuka dan di halaman sekitar rumah. Kebiasaan makan tanpa cuci tangan, bermain-main di tanah akan menyebabkan anak terus menerus mendapat reinfeksi. Dengan demikian, golongan rawan infeksi kedua spesies cacing ini adalah anak balita. [6]

Di daerah endemi dengan insiden Ascaris dan Trichuris tinggi, terjadi penularan secara terus menerus. Transmisi dipengaruhi oleh berbagai hal yang menguntungkan parasit, seperti keadaan tanah dan iklim yang sesuai. Kedua spesies cacing ini memerlukan tanah liat untuk berkembang. Telur A.lumbricoides yang telah dibuahi dan jatuh ke tanah yang sesuai, menjadi matang dalam waktu 3 minggu pada suhu optimum 25-30 C. Telur T.trichiura akan matang dalam 3-6 minggu pada suhu optimum $30 \mathrm{C}$. Telur matang kedua spesies ini tidak menetas di dalam tanah dan dapat bertahan hidup beberapa tahun, khususnya telur A.lumbricoides. Selain keadaan tanah dan iklim yang sesuai, kondisi endemi juga dipengaruhi oleh jumlah telur yang dapat hidup sampai menjadi bentuk infektif dan masuk ke dalam hospes. [7] 
Jumlah telur yang dihasilkan satu ekor cacing betina A.lumbricoides 200.000 sehari,

T.trichiura 5000 sehari, dan cacing tambang 9000-10.000 sehari. Semakin banyak telur ditemukan di sumber kontaminasi (tanah, debu, sayuran, dll), semakin tinggi derajat endemisitas di suatu daerah dengan infeksi yang semakin berat. Pada umumnya tidak ada perbedaan prevalensi infeksi Ascaris dan Trichuris antara laki-laki dan perempuan. [8]

Prevalensi cacing tambang berkisar 30-50\% di berbagai daerah di Indonesia. Prevalensi yang lebih tinggi ditemukan di daerah perkebunan seperti di Sukabumi, Jawa Barat $(93,1 \%)$ dan di perkebunan kopi di Jawa Timur (80,69\%). Prevalensi infeksi cacing tambang cenderung meningkat sesuai umur. Tingginya prevalensi juga dipengaruhi oleh sifat pekerjaan karyawan atau penduduk. Sebagai contoh dapat dikemukakan sebagai berikut: kelompok karyawan yang mengolah tanah di perkebunan teh atau karet akan terus menerus terpapar kontaminasi. [9]

Cacing tambang memerlukan tanah pasir yang gembur, tercampur humus dan terlindung dari sinar matahari langsung. Telur cacing tambang menetas menjadi larva rhabditiform dalam waktu 24-36 jam untuk kemudian pada hari ke 5-8 menjadi bentuk filariform yang infektif. (Tabel 1) Larva filariform ini dapat bertahan 7-8 minggu di tanah dan harus menembus kulit manusia untuk meneruskan siklus hidupnya. Larva S.stercoralis berkembang lebih cepat dari pada larva cacing tambang. Dalam waktu 34-48 jam terbentul larva filariforma yang infektif. Larva ini mempunyai kelangsungan hidup yang pendek di tanah, yaitu 1-2 minggu. Namun, cacing ini mempunyai satu siklus bentuk bebas di tanah yang terus menerus menghasilkan bentuk infektif sehingga perkembangan bentuk bebas di tanah dapat mencapai endemisitas tinggi. Larva ketiga spesies ini memerlukan oksigen untuk pertumbuhannya, oleh karena itu olahan tanah dalam bentuk apapun di lahan pertanian dan perkebunan akan menguntungkan pertumbuhan larva. [10]

\section{Kesimpulan}

Berdasarkan tinjauan di atas, dapat disimpulkan bahwa kondisi tanah gembur atau liat seperti pasir dan humus adalah tanah yang baik untuk pertumbuhan larva cacing atau parasit lain. Suhu optimal untuk pertumbuhan masing-masing spesies berbeda, tergantung siklus hidupnya. Kondisi lembab dan teduh juga berperan dalam berlangsungnya daur hidup parasit. Untuk itu, modifikasi lingkungan sangat diperlukan untuk mencegah transmisi penyakit infeksi penyakit, khususnya di wilayah dengan iklim tropis seperti di Indonesia. 


\section{Daftar Pustaka}

1. O'lorcain P, Holland CV. The public health importance of Ascaris lumbricoides. Parasitol 2014; 121:S51-71.

2. Despommier D. Toxocariasis: clinical aspects, epidemiology, medical ecology, and molecular aspects. Clin Microbiol Rev 2015; 16(2): 265-72

3. Magnaval JF, Glickman LT, DOrchies P, Morassin B. Highlights of human toxocariasis. The Korean J Parasitol 2016; 39(1): 1-11

4. Crompton DWT. The public health importance of hookworm disease. Parasitology. 2017; 121: S39-50

5. Hotez PJ, Brooker S, Bethony JM, Bottazzi ME, Loukas A, Xiao S. Hookworma infection. New England J Med. 2018; 351; 8: 799-807

6. Stephenson LS, Holland CV, Cooper ES. The public health significance of Trichuris trichiura. Parasitol 2019; 121: S73-95

7. Ngwese, M. M., Manouana, G. P., Moure, P. A. N., Ramharter, M., Esen, M., Adégnika, A.A. (2020). Diagnostic techniques of soil-transmitted helminths: Impact on control measures. Tropical Medicine and Infectious Disease, 5(2). https://doi.org/10.3390/tropical

8. Glinz, D., Silué, K. D., Knopp, S., Lohourignon, L. K., Yao, K. P., Steinmann, P., Rinaldi, L., Cringoli, G., N'Goran, E. K., \& Utzinger, J. (2010). Comparing diagnostic accuracy of Kato-Katz, Koga Agar Plate, Ether-Concentration, and FLOTAC for Schistosoma mansoni and Soil-transmitted helminths. PLoS Neglected Tropical Diseases, 4(7). https://doi.org/10.1371/journal.pntd.0000754

9. Lim, M. D., Brooker, S. J., Belizario, V. Y., Gay-Andrieu, F., Gilleard, J., Levecke, B., van Lieshout, L., Medley, G. F., Mekonnen, Z., Mirams, G., Njenga, S. M., Odiere, M. R., Rudge, J. W., Stuyver, L., Vercruysse, J., Vlaminck, J., \& Walson, J. L. (2018). Diagnostic tools for soil-transmitted helminths control and elimination programs: A pathway for diagnostic product development. PLoS Neglected Tropical Diseases, 12(3), 1-18. https://doi.org/10.1371/journal.pntd.0006213

10. Cringoli, G., Rinaldi, L., Maurelli, M. P., \& Utzinger, J. (2010). FLOTAC: New multivalent techniques for qualitative and quantitative copromicroscopic diagnosis of parasites in animals and humans. Nature Protocols, 5(3), 503-515. https://doi.org/10.1038/nprot.2009.235 